\title{
Remoção da adstringência de frutos de caquizeiro 'Giombo' sob diferentes temperaturas ${ }^{(1)}$
}

\author{
Lucimara Rogéria Antoniolli(2), Paulo Roberto de Camargo e Castro(3), Ricardo Alfredo Kluge ${ }^{(3)}$ \\ e João Alexio Scarpare Filho(4)
}

\begin{abstract}
Resumo - O objetivo deste trabalho foi avaliar o efeito de diferentes temperaturas durante o período de exposição ao vapor de álcool etílico sobre a qualidade dos frutos de caquizeiro cultivar Giombo, Os frutos foram expostos ao vapor de álcool etílico durante 42 horas, sob temperaturas de 10, 20 ou $30^{\circ} \mathrm{C}$ e $95 \%$ de umidade relativa. As características químicas e físicas dos frutos foram avaliadas durante nove dias, em intervalos de três dias. As variáveis analisadas foram: grau de taninos solúveis, firmeza da polpa, perda de matéria fresca, sólidos solúveis totais, acidez total titulável e teor de ácido ascórbico. $\mathrm{O}$ tratamento para remoção da adstringência pode ser realizado a 10,20 ou $30^{\circ} \mathrm{C}$, por 42 horas Constatou-se grau de taninos solúveis muito baixo ao sexto dia após o tratamento. A temperatura de $30^{\circ} \mathrm{C}$ promoveu maior rapidez no processo de perda da adstringência, mas os frutos apresentaram menor firmeza de polpa e maior perda de matéria fresca que os frutos submetidos a 20 ou $10^{\circ} \mathrm{C}$.
\end{abstract}

Termos para indexação: Diospyros kaki, substância tanante

\section{Astringency removal of 'Giombo' persimmon fruits submitted to different temperatures}

\begin{abstract}
The purpose of this research was to study the effect of different temperatures during the exposure period to ethyl alcohol vapor on quality of persimmon fruits cv. Giombo. Fruits were exposed to alcohol vapor for 42 hours at 10,20 , or $30^{\circ} \mathrm{C}$ and $95 \% \mathrm{RH}$. Chemical and physical characteristics of fruits were measured for nine days, at three day intervals. Soluble tannin degree, flesh firmness, water loss, soluble solids, titratable acidity and ascorbic acid content were measured. Treatment to astringency removal can be accomplished under temperatures of 10,20 or $30^{\circ} \mathrm{C}$, for 42 hours. Degree of soluble tannins was very low at the sixth day after the treatment. The temperature of $30^{\circ} \mathrm{C}$ promoted higher speed in the process of astringency loss; however, the fruits showed decrease in the flesh firmness and higher-up water loss to the fruits submitted to 20 or $10^{\circ} \mathrm{C}$.
\end{abstract}

Index terms: Diospyros kaki, tanning agents.

\section{Introdução}

O Estado de São Paulo mantém a liderança entre os Estados brasileiros produtores de caqui (Diospyros kaki L.), sendo responsável por

\footnotetext{
(1) Aceito para publicação em 18 de maio de 2001.

(2) Universidade Estadual de Campinas, Faculdade de Engenharia Agrícola, Dep. de Pré-Processamento de Produtos Agropecuários, Caixa Postal 6011, CEP 13083-970 Campinas, SP. E-mail: 1rantoni@agr.unicamp.br

(3) Esalq, Dep. de Ciências Biológicas, Caixa Postal 9 , CEP 13418-900 Piracicaba, SP.

E-mail: prccastr@carpa.ciagri.usp.br, rakluge@carpa.ciagri.usp.br

(4) Esalq, Dep. de Produção vegetal.

E-mail: jascarpa@carpa.ciagri.usp.br
}

aproximadamente $50 \%$ da produção nacional (Campo-Dall'Orto et al., 1996; Simão, 1998).

Entre as cultivares recomendadas para o cultivo comercial no Estado de São Paulo, encontra-se a Giombo, classificada por Ito (1971) como pertencente ao tipo PCA (polinização constante e adstringente). Por outro lado, Martins \& Pereira (1989) classificam esta cultivar como pertencente ao tipo variável (PV), apresentando frutos com polpa bastante taninosa quando partenocárpicos, e sem adstringência, quando com sementes. A cultivar apresenta alta produtividade, sendo considerada de maturação tardia, com período de colheita iniciando-se no mês de março e estendendo-se até fins de maio (Martins \& Pereira, 1989) 
A adstringência é uma característica comum em frutos imaturos de caquizeiro (Taylor, 1993). No entanto, os frutos da cultivar Giombo conservam essa característica mesmo quando maduros, o que diminui sua aceitação no mercado, necessitando, portanto, de um processo artificial de remoção da adstringência.

A necessidade de obtenção de frutos destanizados num curto período de tempo, associada à manutenção da firmeza da polpa durante a vida pós-colheita, tem conduzido à procura por agentes eficientes e práticos, capazes de promover a remoção da adstringência e manter as qualidades desejáveis dos frutos (Antoniolli, 1999). O álcool etílico vem sendo o produto mais utilizado, por possibilitar a obtenção de frutos com boa firmeza de polpa após a destanização (Martins \& Pereira, 1989; Biasi \& Gerhardt, 1992), além da simplicidade de execução do processo. A firmeza da polpa é uma característica importante para a cultivar Giombo, cujos frutos são consumidos com polpa firme (Antoniolli, 1999). De acordo com Pesis et al. (1986), caquis com valor de firmeza inferior a $5,0 \mathrm{~kg} \mathrm{~cm}^{-2}$ são considerados moles.

O tratamento com álcool etílico ou outros agentes destanizadores, como vinagre, água de cal, etileno e carbureto de cálcio, estimula o acúmulo de compostos voláteis na polpa dos frutos, como etanol e acetaldeído. Estas substâncias, especialmente o acetaldeído, induzem os taninos solúveis a se polimerizarem e formarem complexos insolúveis, resultando, com isso, na perda da adstringência (Sugiura \& Tomana, 1983; Vidrih et al., 1994).

Na prática, o processo de remoção da adstringência de caquis vem sendo realizado sem controle de temperatura no ambiente de tratamento, o que tem conduzido, invariavelmente, a resultados indesejáveis, principalmente amolecimento excessivo dos frutos.

O objetivo deste trabalho foi avaliar o efeito de diferentes temperaturas durante o período de exposição ao vapor de álcool etílico, na remoção da adstringência e na manutenção da qualidade dos frutos de caquizeiro ‘Giombo'.

\section{Material e Métodos}

Os frutos, com coloração 100\% alaranjada, foram colhidos no início do mês de maio de 1998, em pomar comercial localizado no Município de Guapiara, SP. Após a colhei- ta, os frutos foram acondicionados em caixas de papelão e transportados, no mesmo dia, ao Laboratório de Fisiologia Pós-Colheita do Departamento de Ciências Biológicas da Escola Superior de Agricultura Luiz de Queiroz, Piracicaba, $\mathrm{SP}$, onde foram padronizados quanto à coloração, tamanho e fitossanidade.

Foram selecionados 180 frutos e acondicionados em bandejas de isopor ( $144 \times 208 \mathrm{~mm}$ ), totalizando 36 bandejas, contendo cinco frutos cada uma.

A remoção da adstringência foi realizada mediante a exposição dos frutos ao vapor de álcool etílico hidratado 92,8 $8^{\circ} \mathrm{INPM}$ (álcool comercial) em câmaras BOD (Biologic Oxygen Demand, Modelo TE 390-Tecnal) contendo $3,85 \mathrm{~mL}$ de álcool $\mathrm{L}^{-1}$ de câmara (ou seja, $3,85 \mathrm{~L} \mathrm{~m}^{-3}$ ). Os frutos permaneceram expostos ao vapor de álcool etílico durante 42 horas, conforme prática comercial, sob 10, $20 \mathrm{e}$ $30^{\circ} \mathrm{C}$. A umidade relativa foi mantida próximo a $95 \%$, através de uma lâmina de água.

Após o tratamento, os frutos foram mantidos em temperatura ambiente $\left(24-25^{\circ} \mathrm{C}\right)$ e aproximadamente $75 \% \mathrm{UR}$, e avaliados a cada três dias, durante nove dias.

$\mathrm{O}$ grau de taninos solúveis $\left(\right.$ Notas- $\mathrm{FeCl}_{3}$ ) foi avaliado visualmente (Campo-Dall'Orto et al., 1996). Os frutos foram cortados transversalmente, utilizando-se uma das partes na prova com a solução indicadora, constatando-se ou não a reação imediata entre os taninos solúveis presentes na polpa e a solução de $\mathrm{FeCl}_{3}$. Em função da coloração verificada na polpa dos frutos, atribuiu-se a seguinte escala de notas: 5 - grau elevado de taninos solúveis; 4 - grau médio; 3 - grau baixo; 2 - grau muito baixo; 1 - grau não detectável. A firmeza de polpa $\left(\mathrm{kg} \mathrm{cm}^{-2}\right)$ foi medida com penetrômetro EFFE-GI, com ponteira de $6,5 \mathrm{~mm}$ de diâmetro, efetuando-se duas leituras em lados opostos na região equatorial dos frutos, após a remoção de uma pequena área da casca. Associou-se o início do amolecimento da polpa ao valor de firmeza de $5 \mathrm{~kg} \mathrm{~cm}^{-2}$, conforme preconizado por Pesis et al. (1986). A perda de matéria fresca (\%) foi avaliada durante os nove dias após o tratamento, em intervalos de três dias, e calculada pela diferença entre as massas inicial e final, sendo apresentada como porcentagem da massa inicial. Os sólidos solúveis totais $\left({ }^{\circ}\right.$ Brix $)$ foram determinados por refratometria, com correção de temperatura para $20^{\circ} \mathrm{C}$. A acidez total titulável (\% ácido málico) foi determinada através da diluição de $10 \mathrm{~mL}$ da amostra em $90 \mathrm{~mL}$ de água destilada, e posterior titulação com solução de $\mathrm{NaOH}$ a $0,1 \mathrm{~N}$, até $\mathrm{pH} 8,10$. O teor de ácido ascórbico (mg ácido ascórbico $100 \mathrm{~g}^{-1} \mathrm{polpa}$ ) foi determinado conforme Carvalho et al. (1990), o qual se baseia na redução do indicador 2,6-diclorobenzenoindofenol (DCFI) pelo ácido ascórbico. 
Uma amostra representativa dos frutos foi submetida a uma avaliação prévia ao tratamento, objetivando a caracterização inicial dos mesmos.

O delineamento experimental adotado foi o inteiramente casualizado, em esquema fatorial $3 \times 4$ (três temperaturas durante a exposição ao vapor de álcool etílico: 10, 20 e $30^{\circ} \mathrm{C}$, e quatro períodos de avaliação: $0,3,6$ e 9 dias ), com três repetições e com cinco frutos por parcela. Os dados foram submetidos à análise de variância, e as médias referentes à perda de matéria fresca e à acidez total titulável foram comparadas pelo teste de Tukey a $5 \%$ de probabilidade. Realizou-se regressão polinomial para as médias obtidas durante o período de nove dias de avaliação.

\section{Resultados e Discussão}

A análise de variância revelou que a temperatura de destanização influenciou significativamente o teor de taninos solúveis, a firmeza de polpa, a perda de matéria fresca e a acidez, e não influenciou o teor de sólidos solúveis e de ácido ascórbico. O período de avaliação interferiu significativamente sobre quase todas as variáveis, com exceção da firmeza da polpa e do teor de sólidos solúveis. A interação entre os dois fatores estudados, por sua vez, apresentou significância apenas para o teor de taninos solúveis e a firmeza de polpa.

Houve um decréscimo acentuado no grau de taninos solúveis da polpa até o terceiro dia após o tratamento, que prosseguiu, embora de maneira menos intensa, até o sexto dia, estabilizando-se em seguida (Figura 1). Fukushima et al. (1991) também constataram que o tratamento com etanol em caquis 'Hiratanenashi' promoveu uma leve perda da adstringência durante os dois primeiros dias subseqüentes ao tratamento, que se acentuou nos dias seguintes. Nas temperaturas de 10 e $20^{\circ} \mathrm{C}$, o valor 2 da escala de notas, considerado como grau muito baixo de taninos solúveis, e, portanto, aceitável para o consumo, foi atingido no sexto dia após o tratamento, enquanto na temperatura de $30^{\circ} \mathrm{C}$ este valor foi alcançado no terceiro dia. A maior rapidez na destanização dos frutos submetidos a $30^{\circ} \mathrm{C}$ deveu-se à maior velocidade de evaporação do álcool etílico, e, conseqüentemente, maior velocidade de acúmulo de etanol e acetaldeído na polpa dos frutos, responsáveis pela polimerização dos taninos solúveis. Kato (1987) também verificou maior velocidade de redu- ção da adstringência com o aumento da temperatura.

A utilização de temperaturas iguais ou superiores a $30^{\circ} \mathrm{C}$, como é observado na prática, favorece a rápida destanização, mas a firmeza da polpa nessa temperatura é afetada negativamente (Figura 1). Enquanto nas temperaturas de 10 e $20^{\circ} \mathrm{C}$ os frutos mantiveram a firmeza durante os nove dias de avaliação, a $30^{\circ} \mathrm{C}$ houve uma redução na firmeza logo após o tratamento, atingindo valores pouco acima de $6 \mathrm{~kg} \mathrm{~cm}^{-2}$ ao terceiro dia. Kato (1987), avaliando o processo de perda da adstringência em caquis 'Aizumishirazu' e 'Hiratanenashi', também constatou que a qualidade dos frutos tratados com etanol, às temperaturas de 15 a $20^{\circ} \mathrm{C}$, se manteve melhor por um período igual ou superior a 10 dias. Conforme Itamura et al. (1997), os tratamentos utilizados para a remoção da adstringência do caqui aceleram a síntese de etileno, que é o hormônio envolvido em vários processos da maturação, incluindo o amolecimento dos frutos. No presente trabalho, é possível que, nos frutos mantidos a $30^{\circ} \mathrm{C}$, tenha ocorrido intensificação da atividade metabólica acompanhada por maior sínte-

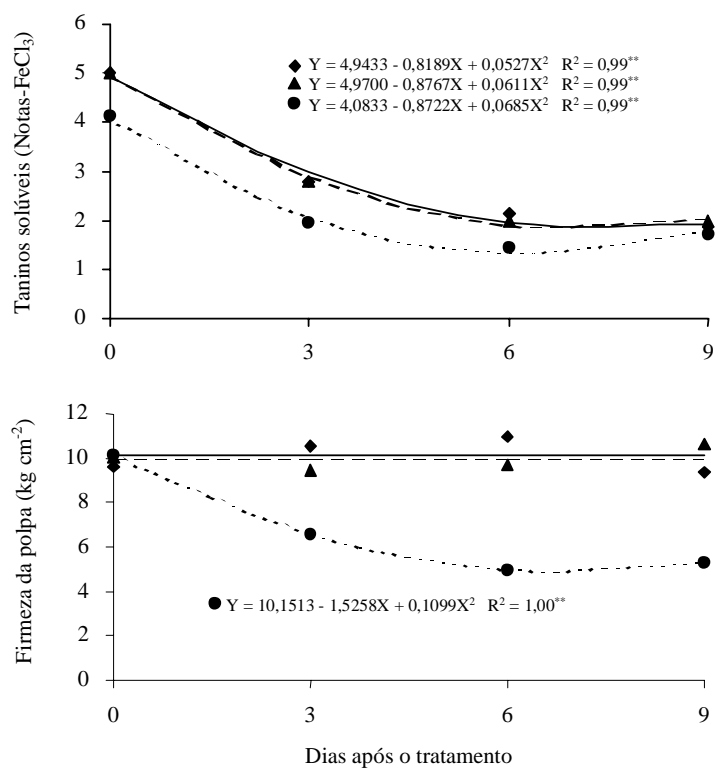

Figura 1. Grau de taninos solúveis (valor inicial de $5,00 \mathrm{~kg} \mathrm{~cm}^{-2}$ ) e firmeza da polpa (valor inicial de $11,24 \mathrm{~kg} \mathrm{~cm}^{-2}$ ) de frutos de caquizeiro 'Giombo', submetidos às temperaturas de destanização de $10(\bullet), 20(\mathbf{A})$ e $30^{\circ} \mathrm{C}(\bullet)$, durante o período de nove dias subseqüentes à exposição ao vapor de álcool etílico.

Pesq. agropec. bras., Brasília, v. 37, n. 5, p. 687-691, maio 2002 
se de etileno, o que proporcionou um incremento na atividade das enzimas pectinolíticas, responsáveis pelo amolecimento do fruto. Segundo Abeles et al. (1992), a temperatura ótima para a produção de etileno é próxima a $30^{\circ} \mathrm{C}$. Embora os frutos submetidos a $30^{\circ} \mathrm{C}$ tenham apresentado menor firmeza que os mantidos a 10 e $20^{\circ} \mathrm{C}$, verifica-se que mesmo os menores valores de firmeza são superiores ao valor de $5 \mathrm{~kg} \mathrm{~cm}^{-2}$ (Figura 1), estabelecido como o limite de firmeza aceitável para frutos da cultivar Giombo, abaixo do qual inicia-se o amolecimento da polpa. As possíveis desvantagens de tais frutos são: menor resistência ao transporte e menor vida útil.

Outra desvantagem da destanização a $30^{\circ} \mathrm{C}$ é o aumento na perda de matéria fresca (Figura 2). Os frutos submetidos a $30^{\circ} \mathrm{C}$ apresentaram perda de matéria fresca significativamente maior que a observada nas demais temperaturas, em decorrência do maior déficit de pressão de vapor entre os tecidos internos do fruto e o ambiente, o que eleva a transpiração. Houve um aumento na perda de matéria fresca em virtude do período de avaliação, constatando-se, ao final de nove dias, uma perda de matéria fresca equivalente a $8,85 \%$ da massa inicial.

Não houve diferença estatística significativa entre os teores de sólidos solúveis totais. Os valores situaram-se entre 17,82 e $18,36^{\circ}$ Brix. Esse resultado está, provavelmente, relacionado à respiração do fruto, que utilizou os açúcares como substrato para o processo. A perda de matéria fresca verificada nos frutos, que normalmente faz com que o teor de sólidos solúveis totais se eleve, provavelmente contrabalançou as perdas dos carboidratos utilizados no processo respiratório, havendo, portanto, pouca variação na variável analisada.

Os frutos submetidos a $30^{\circ} \mathrm{C}$ apresentaram teor de acidez estatisticamente inferior ao verificado nos frutos mantidos a $10^{\circ} \mathrm{C}$, enquanto os frutos submetidos a $20^{\circ} \mathrm{C}$ não diferiram dos demais quanto à acidez total titulável (Figura 3). A maior perda de ATT na maior temperatura de destanização está relacionada ao maior metabolismo dos frutos, que, possivelmente, utilizaram maior quantidade de ácidos como substrato na respiração. Houve diminuição na acidez da polpa dos frutos durante os nove dias subseqüentes ao tratamento (Figura 3 ).

O teor de ácido ascórbico não variou em função da temperatura utilizada no processo de destanização. Entretanto, houve redução nesta variável em função do tempo após o tratamento (Figura 4). Taira et al.
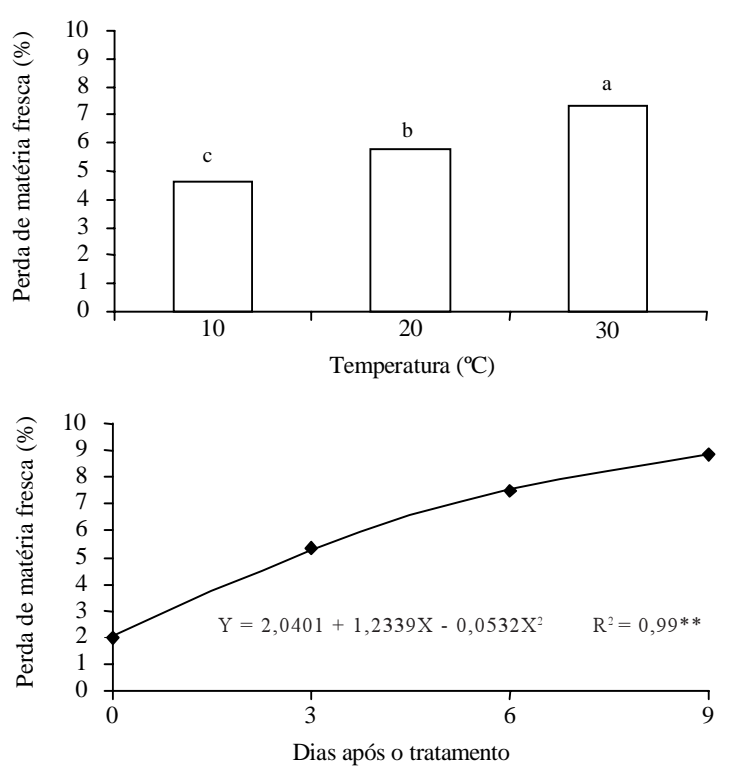

Figura 2. Perda de matéria fresca de frutos de caquizeiro 'Giombo', sob exposição ao vapor de álcool etílico em diferentes temperaturas e durante o período de nove dias subseqüentes ao tratamento (médias seguidas pela mesma letra não diferem entre si pelo teste de Tukey a 5\% de probabilidade)


Figura 3. Acidez total titulável (valor inicial de $0,1251 \%$ ácido málico) de frutos de caquizeiro 'Giombo', sob exposição ao vapor de álcool etílico, em diferentes temperaturas e durante o período de nove dias subseqüentes à exposição ao vapor de álcool etílico (médias seguidas pela mesma letra não diferem entre si pelo teste de Tukey a 5\% de probabilidade). 


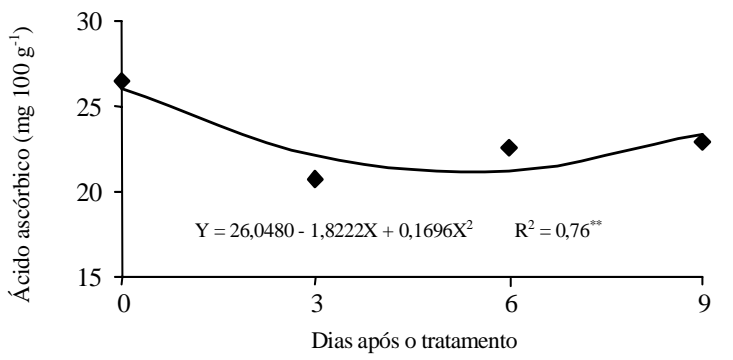

Figura 4. Teor de ácido ascórbico (valor inicial de $28,55 \mathrm{mg} 100 \mathrm{~g}^{-1}$ ) de frutos de caquizeiro 'Giombo', durante o período de nove dias subseqüentes à exposição ao vapor de álcool etílico.

(1987) também constataram pequena alteração nos teores de ácido ascórbico de frutos de caquizeiro que tiveram sua adstringência removida mediante $o$ tratamento com álcool em pós-colheita.

\section{Conclusões}

1. A remoção da adstringência mediante a exposição de caquis 'Giombo' ao vapor de álcool etílico pode ser realizada durante 42 horas sob temperatura de 10 ou $20^{\circ} \mathrm{C}$

2. A temperatura de $30^{\circ} \mathrm{C}$ promove maior rapidez no processo de perda da adstringência, mas os frutos apresentam menor firmeza de polpa e maior perda de matéria fresca do que os frutos submetidos a 20 ou $10^{\circ} \mathrm{C}$.

\section{Referências}

ABELES, F. B.; MORGAN, P. W.; SALVEIT JUNIOR, M. E. Ethylene in plant biology. San Diego: Academic, 1992. $414 \mathrm{p}$

ANTONIOLLI, L. R. Remocão da adstringência e armazenamento refrigerado de frutos de caquizeiro (Diospyros kaki L.) cv. Giombo. 1999. 83 f. Dissertação (Mestrado) - Escola Superior de Agricultura Luiz de Queiroz, Piracicaba.

BIASI, L. A.; GERHARDT, I. R. Efeito da aplicação de vinagre, álcool e ethephon na destanização de caquis cv. Okira. Revista Brasileira de Fruticultura, Cruz das Almas, v. 14, n. 2, p. 31-36, 1992.

CAMPO-DALL'ORTO, F. A.; OJIMA, M.; BARBOSA, W.; ZULLO, M. A. T. Novo processo de avaliação da adstringência dos frutos no melhoramento do caquizeiro. Bragantia, Campinas, v. 55, n. 2, p. 237-243, 1996
CARVALHO, C. R. L.; MANTOVANI, D. M. B.; CARVALHO, P. R. N.; MORAES, R. M. M. Análises químicas de alimentos. Campinas: Instituto de Tecnologia de Alimentos, 1990. 121 p. (Manual Técnico)

FUKUSHIMA, T.; KITAMURA, T.; MURAYAMA, H.; YOSHIDA, T. Mechanisms of astringency removal by ethanol treatment in 'Hiratanenashi' kaki fruits. Journal of the Japanese Society for Horticultural Science, Kyoto, v. 60, n. 3, p. 685-694, 1991

ITAMURA, H.; OHHO, Y.; YAMAMURA, H. Characteristics of fruit softening in Japanese persimmon 'Saijo'. Acta Horticulturae, Leuven, n. 436, p. 179-188, 1997.

ITO, S. The persimmon. In: HULME, A. C. (Ed.). The biochemistry of fruits and their products. London: Academic, 1971. v. 2, cap. 8, p. 281-301

$\mathrm{KATO}, \mathrm{K}$. Astringency removal and ripening as related to temperature during the astringency removal by ethanol in persimmon fruits. Journal of the Japanese Society for Horticultural Science, Kyoto, v. 55, n. 4, p. 498-509, 1987

MARTINS, F. P.; PEREIRA, F. M. Cultura do caquizeiro. Jaboticabal: Funep, 1989. 71 p.

PESIS, E.; LEVI, A.; BEN-ARIE, R. Deastringency of persimmon fruits by creating a modified atmosphere in polyethylene bags. Journal of Food Science, Chicago, v. 51, n. 4, p. 1014-1016, 1041, 1986.

SIMÃO, S. Tratado de fruticultura. Piracicaba: Fealq 1998. $760 \mathrm{p}$.

SUGIURA, A.; TOMANA, T. Relationships of ethanol production by seeds of different types of Japanese persimmons and their tannin content. HortScience, Alexandria, v. 18, n. 3, p. 319-321, 1983

TAIRA, S.; KUBO, Y.; SUGIURA, A.; TOMANA, T. Comparative studies of postharvest fruit quality and storage quality in Japanese persimmon (Diospyros kaki L. cv. Hiratanenashi) in relation to different methods for removal of astringency. Journal of the Japanese Society for Horticultural Science, Kyoto, v. 56, n. 2, p. 215-221, 1987

TAYLOR, J. E. Exotics. In: SEYMOUR, G. B.; TAYLOR, J. E.; TUCKER, G. A. Biochemistry of fruit ripening. London: Chapman \& Hall, 1993. p. 151-186.

VIDRIH, R.; SIMCIC, M.; HRIBAR, J.; PLESTENJAK, A. Astringency removal by high $\mathrm{CO}_{2}$ treatment in persimmon fruit (Diospyros kaki). Acta Horticulturae, Leuven, n. 368, p. 652-656, 1994. 